\title{
REVISÃO DE LITERATURA SOBRE A EXPERIMENTAÇÃO INVESTIGATIVA NO ENSINO DE CIÊNCIAS
}

\author{
LITERATURE REVIEW ON INVESTIGATIVE EXPERIMENTATION \\ IN SCIENCE TEACHING
}

\section{REVISIÓN DE LA LITERATURA SOBRE LA EXPERIMENTACIÓN INVESTIGADORA EN LA ENSEÑNAZA DE CIENCIAS}

\author{
Ana Flávia Correa LeÃo ${ }^{\mathrm{I}}$ \\ MARA ElisÂNGELA JAPPE GOI ${ }^{\mathrm{I}}$ \\ ${ }^{\text {I } U n i v e r s i d a d e ~ F e d e r a l ~ d o ~ P a m p a ~(U N I P A M P A), ~ C a c ̧ a p a v a ~ d o ~ S u l / R S-B r a s i l ~}$
}

RESUmo Este trabalho tem por objetivo realizar uma revisão de literatura sobre o assunto Experimentação Investigativa no Ensino de Ciências. Para isso, fez-se uma busca em 6 periódicos de classificação Qualis Capes A1, A2 e B1 de Ensino de Ciências, no período de 2010 a 2019. Nessa busca foram encontrados 83 artigos sobre Experimentação no Ensino de Ciências, sendo que apenas 22 tratavam da Experimentação Investigativa. A partir desses artigos, foram realizadas as leituras que emergiram em duas categorias de análise: i) Experimentação Investigativa na Formação Inicial e Continuada de Professores; ii) Experimentação Investigativa na Educação Básica. Os dados dos artigos foram analisados com embasamento da Análise de Conteúdo de Bardin e, a partir da leitura, pode-se constatar que a Experimentação Investigativa demonstra potencial como estratégia metodológica nos processos de ensino e aprendizagem no Ensino de Ciências e na formação de alunos críticos e investigativos, contribuindo na construção do conhecimento científico.

Palavras-chave: Experimentação Investigativa; Ensino de CiênCias; Formação de Professores; EduCaÇão BÁSICA.

ABSTRACT This work aims at reviewing literature about Investigative Experimentation in Science Teaching. For that, a search was made in 6 journals of Qualis Capes A1, A2 and B1 classification of Science Teaching, from 2010 to 2019. In this search, 83 articles were found on Experimentation in Science Teaching, which only 22 dealt with of Investigative Experimentation. Readings these articles emerged two categories of analysis: i) Investigative Experimentation in Initial and Continuous Teachers' Education; ii) Investigative Experimentation in Basic Education. The data of the articles were analyzed using Bardin's 
Content Analysis and it can be seen that the Investigative Experimentation shows potential as a methodological strategy in the teaching and learning processes in Science Teaching and in formation of critical and investigative students, contributing to the construction of scientific knowledge.

Keywords: Investigative Experimentation; Science teaching; Teacher training; BASIC EDUCATION.

RESUMEN Este trabajo tiene como objetivo realizar una revisión de la literatura sobre el tema Experimentación investigativa em la enseñanza de las ciencias. Para ello, se realizó una búsqueda en 6 revistas de clasificación Qualis Capes A1, A2 y B1 de Enseñanza de las Ciencias, en el período de 2010 a 2019. Em esta búsqueda, se encontraron 83 artículos sobre Experimentación em Enseñanza de las Ciencias, de los cuales solo 22 trataron de experimentación investigativa. En estos artículos, se realizaron lecturas y surgieron dos categorías de análisis: i) Experimentación investigativa en la formación inicial y continua del docente; ii) Experimentación investigativa en educación básica. Los datos de los artículos se analizaron mediante el Análisis de contenido de Bardin y, al leerlo, se puede ver que la Experimentación investigativa muestra, en los resultados, el potencial como estrategia metodológica en los procesos de enseñanza y aprendizaje en la enseñanza de las ciencias y em formación de estudiantes críticos e investigativos, contribuyendo a la construcción del conocimiento científico.

Palabras Clave: Experimentación inVestigativa; EnseñanZa de Ciencias; Formación DEL PROFESORADO; EDUCACIÓN BÁSICA.

\section{INTRODUÇÃo}

No contexto atual, diante de pandemias e catástrofes ambientais, vivemos em uma sociedade em que descobertas científicas e tecnológicas se fazem cada vez mais necessárias. No entanto, o Ensino de Ciências tem sido motivo de constantes análises devido às dificuldades encontradas por professores e alunos durante o processo de ensino e aprendizagem. Essas dificuldades fazem com que haja uma imagem negativa e de desinteresse por parte dos alunos, causando um declínio em estudos e profissões relacionadas à ciência e à tecnologia (SOLBES; MONTSERRAT; FURIÓ, 2007). Os próprios alunos apontam as causas do desinteresse pelo aprendizado de Ciências, destacando um ensino descontextualizado de seu ambiente, o uso demasiado de metodologias passivas e a realização de poucas práticas de laboratório (FURIÓ, 2005). Diante desse contexto, os professores podem enfrentar o desafio de aproximar os conteúdos da disciplina de Ciências da Natureza à realidade dos alunos, não apenas para aumentar as habilidades científicas, mas também para capacitar cidadãos responsáveis, preocupados e críticos diante de situações relacionadas com à ciência.

Para isso, os conteúdos a serem trabalhados em sala de aula podem ter um significado humano e social de modo que provoque interesse no aluno. Assim, permitindo uma leitura mais crítica do mundo físico e social, proporcionando reflexão, compreensão, discussão e ação sobre o mundo que habita (HERRERO; BAUTISTA, 2019). 
Nessa ótica, uma das estratégias didáticas difundidas são as atividades experimentais, cuja principal característica, por muito tempo, foi a de verificar ou confirmar alguma lei ou teoria, além de buscar na prática o que foi ensinado pelo professor e aprendido pelo aluno em sala de aula. Este tipo de atividade é orientada por roteiros pré-determinados, tendo resultados previsíveis e suas explicações para tais fenômenos, na maioria das vezes, já conhecidas pelos alunos, sem propor raciocínio e questionamentos. De acordo com Suart e Marcondes (2009, p.53), "[...] as atividades experimentais podem contribuir para o desenvolvimento de habilidade cognitivas, desde que sejam planejadas e executadas de forma a privilegiar a participação do aluno".

Uma alternativa para esse tipo de atividade seria propor o ensino a partir de atividades experimentais investigativas, de maneira que os alunos são colocados em situações de realizar pequenas pesquisas. Carvalho et al. (2009) conceitua a experimentação investigativa como um método de ensino que desperta o interesse do discente e favorece uma aprendizagem diferenciada, na qual as falas, concepções e ideias dos estudantes são valorizadas, contribuindo na construção do conhecimento e na promoção do pensamento crítico-reflexivo.

Na visão de Maués e Lima (2006), os alunos que são colocados em processos investigativos envolvem-se com a sua aprendizagem, constroem questões, levantam hipóteses, analisam evidências e comunicam os seus resultados. Em um ambiente de ensino e aprendizagem baseado na investigação, os estudantes e os professores compartilham a responsabilidade de aprender e colaborar com a construção do conhecimento. Os professores deixam de ser os únicos a fornecer conhecimento e os estudantes deixam de desempenhar papéis passivos de meros receptores de informação. Contudo, a realização deste tipo de atividade se torna mais significativa, proveitosa e motivadora para os alunos se for contextualizada com o dia a dia. Conforme Medeiros e Lobato (2010, p. 66), "a contextualização do ensino tem relação com a motivação do aluno, por dar sentido àquilo que ele aprende, fazendo com que relacione o que está sendo ensinado com a sua experiência cotidiana". Nessa perspectiva, o ensino ministrado por atividades experimentais investigativas torna-se uma importante estratégia de ensino e de aprendizagem.

Com o objetivo de realizar uma revisão de literatura sobre o assunto Experimentação Investigativa no Ensino de Ciências, fez-se uma busca de artigos relacionados ao assunto em seis (6) revistas da classificação Qualis Capes A1, A2 e B1, sendo cinco nacionais e um internacional no período de 2010 a 2019, visando aprofundar a temática aqui tratada.

\section{Experimentação no Ensino de Ciências}

A experimentação tem sido utilizada no Ensino de Ciências visando diversos objetivos, como: (i) demonstrar um fenômeno; (ii) confirmar um princípio teórico; (iii) coletar dados, testar hipóteses; (iv) desenvolver habilidades de observação ou medida; (v) adquirir familiaridade com montagens; e, (vi) visualizar um show de luzes, barulhos e fumaça Hodson (1994); Gonçalves e Goi (2018). No entanto, segundo as ideias de Hodson (1988), Ferreira, Corrêa e Silva (2019), a experimentação pode ser explorada para a compreensão de conceitos científicos, para entendimento de aspectos de natureza da ciência e para aproximar a investigação escolar da investigação científica. 
Para Hodson (1994) os experimentos não são suficientes para produzir conhecimentos teóricos e, nem sempre, são necessários. Segundo ele, os experimentos não são independentes de uma teoria, sendo que essa teoria influencia o problema a ser resolvido. No Ensino de Ciências, a experimentação possui objetivos distintos dos experimentos realizados pelos cientistas, visto que os estudantes não fazem observações com o mesmo nível de detalhes e profundidade que os cientistas. Além disso, não dispõem de laboratórios com o mesmo grau de sofisticação (HODSON, 1994) e de um quadro teórico consolidado como os cientistas. No entanto, para que essa função dos experimentos seja atingida, o professor precisa adquirir um entendimento sobre as formas de abordagem da experimentação na Educação Básica e como se dá a sua condução.

Moreira (2011) destaca duas posições profundamente distintas que norteiam a experimentação: a comportamentalista e a construtivista. Sob a ótica comportamentalista, Moreira (2011) argumenta que a aprendizagem se dá através de comportamentos (observáveis e mensuráveis) que são respostas a estímulos exteriores. Portanto, a aprendizagem do aluno se daria por uma mudança de comportamento resultante de estímulos promovidos pelo professor, de forma condicionada e repetitiva, sem considerar aspectos cognitivos para a construção do conhecimento. Segundo Campos e Cachapuz (1997), entre o empirismo-positivista e o racionalismo-construtivista, surgiram várias referências para compreender a natureza da ciência e seu desenvolvimento. Moreira (2011) aponta a Aprendizagem por Descoberta de Jerome Bruner diferente do Modelo de Redescoberta (1950 a 1970) que adotava muitos princípios e conceitos do modelo tradicional, chamado transmissão do conhecimento e o estímulo-resposta, procurando evitar aulas expositivas, preferindo as atividades experimentais com roteiros fechados. Já a Aprendizagem por Descoberta não deve ser limitada a uma aprendizagem mecânica de informação ou de procedimentos, mas sim conduzir o educando ao desenvolvimento da sua capacidade para solucionar problemas e pensar sobre a situação que enfrenta, sendo que nas atividades experimentais não existe um roteiro, eles vão sendo construídos. Despertando, dessa forma, o pensamento crítico reflexivo do aluno, tornando-o sujeito de sua aprendizagem através do modo como levanta hipóteses, discute com os outros colegas, reflete sobre um tema e busca soluções.

Baseados nos estudos de Carvalho et al. (1998), Brito e Fireman (2018), entende-se que a introdução dessa lógica no Ensino de Ciências implica trabalhar os conteúdos científicos em sala de aula em forma de problemas que consideram os procedimentos como: testes de hipóteses, controle de variáveis, observação de evidência, sistematização e socialização de resultados coletivamente. Em outras palavras, implica trabalhar Ciências da Natureza por investigação, constituindo-se de uma perspectiva capaz de tornar o conteúdo mais interessante ao passo que permita ao aluno aprender ciência por meio das suas próprias ações criativas.

Entende-se que o Ensino de Ciências por investigação, por possuir essa peculiaridade de apresentar os conteúdos por meio de problemas em que os alunos são chamados a resolvê-los de forma ativa, é um dos caminhos para o professor conseguir em sua estratégia. Deve-se "[...] tornar o conteúdo mais interessante por trazê-lo para mais perto do universo 
cognitivo não só do aluno, mas do próprio homem, que antes de conhecer cientificamente, constrói historicamente o que conhece" (CASTRO, p. 30, 2016).

Postigo e Greca (2014) referem-se à investigação como uma metodologia viável ajustando-se aos tempos e ao currículo imposto, além do entendimento que os alunos têm dos conceitos científicos abordados se comparado ao alcançado com a metodologia tradicional. Ainda, os estudiosos recomendam iniciar o Ensino da Ciências por investigação desde os primeiros ciclos, bem como os professores que são capazes de transmitir emoção no conhecimento da ciência, para que possam capturar o interesse e a ilusão, necessário para a participação ativa dos alunos do ensino fundamental.

Tais considerações evidenciam que o ensino tradicional é baseado na aprendizagem de conceitos, que os alunos aprendem por repetição e de forma descontextualizada, sem fazer com que as crianças aprendam ao máximo conceitos científicos básicos ou sejam atraídos por eles. As crianças são curiosas para aprender ciência, mas só essa característica não é o suficiente para que gostem de estudá-la. Sendo assim, a experimentação investigativa torna-se uma metodologia importante a ser discutida e aplicada no Ensino de Ciências.

\section{Metodologia}

Com o objetivo de conhecer e categorizar a natureza dos trabalhos realizados, apresenta-se uma revisão bibliográfica de natureza qualitativa (LUDKE; ANDRÉ, 1986) em artigos publicados em periódicos da classificação Qualis Capes A1, A2 e B1, os quais foram escolhidos pela classificação e por tratar do Ensino de Ciências, no período de 2010 a 2019. Nos periódicos, as buscas foram feitas pelo título dos artigos, leitura de resumos e, em alguns casos, leitura do documento na íntegra e pelas palavras-chave: "Atividades Práticas", "Experimentação", "Atividades Investigativas", "Ensino de Ciências" e "Práticas de Laboratório". A análise foi realizada para a categorização dos artigos selecionados e o reagrupamento das informações em categorias mais abrangentes. Para o tratamento de dados, foi utilizada a análise de conteúdo que, para Bardin (2011, p. 131), torna-se necessário saber por qual razão se analisa e se explicita, de modo que possa saber como analisar. Assim, a organização da codificação compreende três escolhas: o recorte (escolha das unidades), a enumeração (escolha das regras de contagem) e a classificação e agregação (escolha das categorias).

Assim, a partir desse experimento metodológico, foram consultados os sistemas de busca presentes na página dos periódicos. Com os artigos selecionados, realizou-se a análise dos mesmos em busca de possíveis justificativas levantadas pelos autores para tratar da Experimentação no Ensino de Ciências. Após essa fase, os artigos analisados foram agrupados em categorias que emergiram das análises dos textos e em seguida foram discutidas individualmente levando em consideração suas implicações para o Ensino de Ciências. Na tabela abaixo estão descritos os periódicos que compõe esta revisão. 
Tabela1: Número total de artigos sobre Experimentação no Ensino de Ciências.

\begin{tabular}{c|c|c}
\hline Revista & Classificação Qualis Capes & Número de Artigos \\
\hline Revista Ciência \& Educação & A1 & 07 \\
\hline $\begin{array}{c}\text { Revista Enseñanza de LasCiên- } \\
\text { cias }\end{array}$ & A1 & 14 \\
\hline $\begin{array}{c}\text { Revista Brasileira de Ensino de } \\
\text { Ciência e Tecnologia }\end{array}$ & A2 & 13 \\
\hline $\begin{array}{c}\text { Revista Brasileira de Pesquisa } \\
\text { em Educação em Ciências }\end{array}$ & A2 & 06 \\
\hline $\begin{array}{c}\text { Revista Experiências em Ensino } \\
\text { de Ciências }\end{array}$ & B1 & 32 \\
\hline $\begin{array}{c}\text { Caderno Brasileiro de Ensino de } \\
\text { Física }\end{array}$ & B1 & 11 \\
\hline Total & & 83 \\
\hline
\end{tabular}

Fonte: Autoras

Da posse dos artigos, fez-se a leitura mais detalhada e emergiram duas categorias de análise: a Experimentação Investigativa na Formação Inicial e Continuada de Professores e a Experimentação Investigativa na Educação Básica. Neste trabalho serão analisadas as duas categorias. Buscou-se diferenciar, classificar e reagrupar os elementos de cada um dos artigos sobre Experimentação Investigativa no Ensino de Ciências. Para isso, os artigos foram agrupados levando em consideração o tema tratado em cada um deles.

Como a quantidade de artigos encontrados sobre a Experimentação no Ensino de Ciências foi ampla, fez-se um recorte deixando apenas os 22 artigos relacionados à Experimentação Investigativa no Ensino de Ciências. O Quadro 1, demonstra os artigos selecionados e dos quais emergiram as categorias de análise.

Quadro 1: Artigos relacionados aos experimentos investigativos

\begin{tabular}{|c|c|c|}
\hline ANO & TÍTULO & AUTORES \\
\hline 2011 & $\begin{array}{l}\text { Uma abordagem para projetar pesquisa através de ex- } \\
\text { perimentos de ensino. }\end{array}$ & $\begin{array}{l}\text { GONZÁLEZ, M. M.; MARTÍ- } \\
\text { NEZ, E. C.; GONZÁLEZ, J. L. } \\
\text { M.; MARTÍNEZ, E. C. }\end{array}$ \\
\hline 2011 & $\begin{array}{l}\text { Trabalho Experimental como possível gerador de co- } \\
\text { nhecimento no ensino de física. }\end{array}$ & JAIME, E. A. ESCUDERO, C. \\
\hline 2012 & $\begin{array}{l}\text { A caracterização do ambiente de aprendizagem em } \\
\text { um laboratório de química geral através de métodos } \\
\text { de pesquisa social. }\end{array}$ & $\begin{array}{l}\text { MOLINA, J. A. L.; JAIME, J. L.; } \\
\text { BERZOSA, I. S. }\end{array}$ \\
\hline 2012 & $\begin{array}{l}\text { Perguntas de alunos do ensino médio a dispositivos } \\
\text { experimentais. }\end{array}$ & $\begin{array}{l}\text { VALOIS, T. T.; DUQUE, K. J.; } \\
\text { ISHIWA, K.; SÁNCHEZ, G.; } \\
\text { PORTOLÉS, J. J. S.; LÓPEZ, V. S. }\end{array}$ \\
\hline 2013 & $\begin{array}{l}\text { Desafios enfrentados por professores na implementa- } \\
\text { ção de atividades investigativas nas aulas de ciências. }\end{array}$ & $\begin{array}{l}\text { GOUW, A. M. S.; FRANZOLI- } \\
\text { NI, F.; FEJES, M. E. }\end{array}$ \\
\hline
\end{tabular}




\begin{tabular}{|c|c|c|}
\hline ANO & TÍTULO & AUTORES \\
\hline 2013 & $\begin{array}{l}\text { Problematização de atividades experimentais no ensi- } \\
\text { no e desenvolvimento profissional de formadores de } \\
\text { professores de química. }\end{array}$ & $\begin{array}{l}\text { MARQUES, C. A.; GONÇAL- } \\
\text { VES, F. P. }\end{array}$ \\
\hline \multicolumn{2}{|c|}{$\begin{array}{l}2013 \\
\text { Sequências experimentais de abertura e redação de artigos } \\
\text { em laboratório: um itinerário para melhorar o trabalho práti- } \\
\text { co em laboratório. }\end{array}$} & CASAL, J. D. \\
\hline 2014 & $\begin{array}{l}\text { Pensando a natureza da ciência a partir de atividades } \\
\text { experimentais investigativas numa escola de forma- } \\
\text { ção profissional. }\end{array}$ & SENRA, C. P. \\
\hline 2014 & $\begin{array}{l}\text { Caracterização de práticas experimentais na escola a } \\
\text { partir do discurso de professores do ensino fundamen- } \\
\text { tal e médio. }\end{array}$ & $\begin{array}{l}\text { MENGASCINI, A. S.; MORDE- } \\
\text { GLIA, C. }\end{array}$ \\
\hline 2015 & $\begin{array}{l}\text { Desafios das atividades de pesquisa aberta em labo- } \\
\text { ratório: articulação do conhecimento teórico e prático } \\
\text { nas práticas científicas. }\end{array}$ & $\begin{array}{l}\text { PÉREZ, B. C.; ALEIXANDRE, } \\
\text { M. P. J. }\end{array}$ \\
\hline 2015 & $\begin{array}{l}\text { Competências e práticas científicas no laboratório de } \\
\text { química: participação de estudantes do ensino médio } \\
\text { em pesquisas. }\end{array}$ & PÉREZ, B. C. \\
\hline 2016 & $\begin{array}{l}\text { Aprendizado de reações químicas através de ativida- } \\
\text { des de pesquisa em laboratório sobre questões da vida } \\
\text { cotidiana. }\end{array}$ & $\begin{array}{l}\text { RODRIGUES, L. G.; PÉREZ, } \\
\text { B. C. }\end{array}$ \\
\hline 2016 & $\begin{array}{l}\text { A atividade investigativa na elaboração e análise } \\
\text { de experimentos didáticos }\end{array}$ & $\begin{array}{l}\text { TOLEDO, E. J. L.; FERREIRA, } \\
\text { L. H. }\end{array}$ \\
\hline 2018 & $\begin{array}{l}\text { Ciência na cozinha. Uma proposta inovadora para } \\
\text { ensinar Física e Química no ensino médio. }\end{array}$ & $\begin{array}{l}\text { MARTÍNEZ, N. G.; MARTÍ- } \\
\text { NEZ, S. G.; MARTIINEZ, P. A.; } \\
\text { RUIZ, L. A. }\end{array}$ \\
\hline 2018 & $\begin{array}{l}\text { A Experimentoteca do Centro de Divulgação Científi- } \\
\text { ca e Cultural (CDCC-USP) e o Ensino por Investiga- } \\
\text { ção: Compromissos Teóricos e Esforços Práticos }\end{array}$ & MORI, R. C.; CURVELO, A. A. S. \\
\hline 2018 & $\begin{array}{l}\text { Ensino de ciências por investigação: uma proposta di- } \\
\text { dática "para além" de conteúdos conceituais }\end{array}$ & BRITO, L. O.; FIREMAN, E. C. \\
\hline 2018 & $\begin{array}{l}\text { O ensino de processos de separação de misturas a par- } \\
\text { tir de situações-problemas e atividades experimentais } \\
\text { investigativas. }\end{array}$ & $\begin{array}{l}\text { FRIGGI, D. A.; CHITOLINA, } \\
\text { M. R. }\end{array}$ \\
\hline 2019 & $\begin{array}{l}\text { Estudo dos roteiros de experimentos disponibilizados em } \\
\text { repositórios virtuais por meio do ensino por investigação }\end{array}$ & $\begin{array}{l}\text { FERREIRA, S.; CORREA, } \\
\text { R. e SILVA, F. C. }\end{array}$ \\
\hline 2019 & $\begin{array}{l}\text { Investigação no ensino médio: sistemas de hidroponia } \\
\text { em horta escolar para discussão de conceitos químicos. }\end{array}$ & $\begin{array}{l}\text { MOURA, K. F. A.; DURÃES, J. } \\
\text { A. S.; SILVA, F. C. }\end{array}$ \\
\hline 2019 & $\begin{array}{l}\text { Ensinando sobre os sentidos químicos. Investigação } \\
\text { sobre uma experiência motivadora. }\end{array}$ & $\begin{array}{l}\text { EDELSZTEIN, V. C.; GALA- } \\
\text { GOVSKY, L. }\end{array}$ \\
\hline 2019 & $\begin{array}{l}\text { Aprenda a interpretar a acidificação dos oceanos com } \\
\text { recursos online e experimentação contextualizada. }\end{array}$ & $\begin{array}{l}\text { RIAL, M. A. L.; MARIA M. ÁL- } \\
\text { VAREZ LIRES, CORREA, A. } \\
\text { A.; RODRÍGUEZ, U. P. }\end{array}$ \\
\hline 2019 & $\begin{array}{l}\text { Uso da contextualização através do uso de demons- } \\
\text { trações experimentais para melhorar a percepção e a } \\
\text { atitude dos futuros professores em relação à química. }\end{array}$ & $\begin{array}{l}\text { HERRERO, J. F. A.; BAUTIS- } \\
\text { TA, C. V. }\end{array}$ \\
\hline
\end{tabular}

Fonte: Autoras 


\section{RESULTADOS E DISCUSSÃo}

Os artigos referentes à Experimentação Investigativa no Ensino de Ciências apontam que há uma preocupação dos autores com os processos de aprendizagem dos estudantes no que se refere à experimentação investigativa. Nesta análise, verificou-se que a experimentação é uma metodologia usada nessa área do conhecimento para qualificar os processos de ensino e de aprendizagem.

A seguir, tratar-se-á da análise das categorias (i) Experimentação Investigativa na Formação Inicial e Continuada de Professores; (ii) Experimentação Investigativa na Educação Básica.

\section{Experimentação Investigativa na Formação Inicial e Continuada de Professores}

Nesta categoria contabilizou-se 11 artigos. Os estudos são baseados na investigação após a implementação de intervenções que buscam o desenvolvimento de processos de aprendizagem através do trabalho experimental, na formação inicial e continuada de professores do Ensino de Ciências (JAIME; ESCUDERO, 2011, JUAN et al., 2012, GONÇALVES; MARQUES, 2013, GOUW et al, 2013, MORDEGLIA; MENGASCINI, 2014, PÉREZ; ALEIXANDRE, 2015, BRITO; FIREMAN, 2018, FERREIRA; CORRÊA; SILVA, 2019, EDELSZTEIN; GALAGOVSKY, 2019, RIAL et al., 2019, HERRERO; BAUTISTA, 2019).

Na pauta das preocupações da educação está a qualidade do ensino ofertado, o perfil dos profissionais formados, as condições das Instituições de Ensino Superior (IES), os recursos disponíveis (físicos, pedagógicos, materiais), o acesso, a permanência, o sucesso dos estudantes do ensino superior e o financiamento das instituições públicas e particulares (BRASIL, 2015). Sendo assim, é importante trabalhar com as metodologias que podem dar sentido ao Ensino de Ciências, pois segundo Brito e Fireman (2018, p. 477):

\footnotetext{
Consideramos anacronismo, em plena metade do século XXI, existir visões simplistas acerca do processo de ensino e aprendizagem. Ensinar é uma atividade complexa que exige do professor, não apenas, o domínio do conteúdo conceitual que irá ensinar. Tais conhecimentos são essenciais para o processo de ensino e aprendizagem, mas, de forma isolada, circunscrito a si mesmo, esse tipo de conteúdo torna a aprendizagem um conjunto de teorizações herméticas, descontextualizadas que por não se associarem a estrutura lógica cognitiva dos alunos são facilmente esquecidos.
}

Ainda, conforme Brito e Fireman (2018), estudos atuais que tratam sobre a natureza da ciência apontam que o conhecimento científico é construído em um processo histórico e social. Este possui a marca de um processo, logo, se conclui que os produtos da ciência são construções que se materializam pela dimensão processual, ou seja, constituem-se pelo saber fazer. Nessa acepção, cabe acentuar a necessidade de o Ensino de Ciências ter como um de seus objetivos "[...] a prática de ajudar os alunos a aprender e fazer ciência, ou, em outras palavras, ensinar aos alunos procedimentos para a aprendizagem de Ciências" (POZO; CRESPO 2009, p. 47). 
Para Jaime e Consuelo (2011), trata-se de entender como o aluno está construindo seus conceitos, através da observação e análise da organização da atividade, nas diferentes etapas da aprendizagem e avaliação. Dependendo do referencial teórico da pesquisa, são consideradas as fontes de informação, orais ou escritas, provenientes de produções individuais ou em grupos, na sala de aula. Para isso, devem ser coletados registros escritos do que os alunos fazem durante o trabalho experimental, descrevendo suas dificuldades, principalmente quando se refere a uma situação específica de um conteúdo.

Conforme Herrero e Bautista (2019), ao usar uma demonstração para aprender novos conteúdos, o aluno deve fazer perguntas sobre o que aconteceu, por que motivos ou razões, e o professor precisará fazer uma pesquisa bibliográfica para dar uma resposta científica ao fenômeno observado na demonstração. Neste momento, uma conexão pode ser estabelecida entre o que já é conhecido (conhecimento prévio) e o que se acabou de aprender (novos conhecimentos). “[...] Deve-se ter em mente que se novos conceitos ou conteúdos não forem relevantes para a estrutura cognitiva do aluno essas novas informações não estarão relacionadas ao conhecimento anterior e, em qualquer caso, essas informações serão simplesmente memorizadas" (NOVAK, 1988). Ainda, segundo Herrero e Bautista (2019), o professor deve dominar o conhecimento específico de sua disciplina, além de ter noção de psicologia educacional, isto é, que saiba como os alunos aprendem.

Segundo Gonçalves e Marques (2013), estudos indicam que no Brasil existem poucas pesquisas sobre a Educação Superior em Ciências, em especial no Ensino de Química, bem como na formação de professores de Ensino Superior (SCHNETZLER, 2002, BRZEZINSKI, 2006, SILVA; SCHNETZLER, 2005). Assim, como ocorre em outros países, essa falta de preocupação estende-se não só na pesquisa educacional, como também nas políticas públicas, deixando de valorizar professores pesquisadores, fazendo com que o Ensino de Ciências não seja abordado de forma investigativa (CAMPANARIO, 2002,2003). Sendo assim, Gonçalves e Marques (2013) apontam aspectos teóricos e metodológicos de uma proposta dialógica e problematizadora baseada em Paulo Freire a partir de uma abordagem epistemológica em que os princípios e valores da educação são independentes do nível de ensino e de aprendizagens. Como Paulo Freire (1977, p. 53) já afirmou: “[...] o diálogo problematizante não depende do conteúdo que será problematizado. Tudo pode ser problematizado". Essas considerações permitem confirmar que tanto a experimentação na formação de professores quanto o conteúdo abordado nas atividades experimentais pode ser tomado como objeto de problematização. Ainda, segundo Gonçalves e Marques (2013), são apontados fatores limitantes para essa metodologia como: estrutura das instituições de ensino, falta de união entre os professores, pesquisa em detrimento do ensino, conhecimento pouco relacionado aos resultados obtidos na investigação e pouco incentivo na elaboração de textos de Divulgação Científica.

Franzolin e Fejes (2013), baseados em uma investigação realizada por dois professores de modalidades diferentes de ensino, a professora em início de carreira e o professor com 23 anos de magistério, obtiveram como resultado da pesquisa que é possível trabalhar com atividades investigativas, tanto com alunos de pouca idade como maiores, utilizando-se, para isso, estratégias adequadas a cada faixa etária. Ainda segundo Franzolin e Fejes (2013), para os professores, a escolha de estratégias didáticas foi um desafio para que as ati- 
vidades investigativas se aproximassem dos modelos de aprendizagem participativa. $\mathrm{O}$ tempo de experiência no magistério dos professores também apontou questões interessantes: a professora, mesmo iniciante, encontrou uma forma de introduzir a questão da investigação, utilizando estratégias em que ela se sentia segura. No caso, ela preparou minuciosamente todas as atividades para que as aulas pudessem ser dirigidas por ela com eficiência; já o professor não se preocupou muito com essa questão, ele organizou as atividades de forma a favorecer a autonomia do aluno. O trabalho em equipe também foi importante para a professora, e pode ser uma interessante estratégia para que o professor iniciante possa organizar atividades dessa natureza. Apesar de utilizarem estratégias diferentes, foi possível verificar que ambos os professores conseguiram trabalhar com o interesse dos alunos, uma vez que estes se mostraram engajados em suas investigações. Assim, verifica-se que as propostas de atividades investigativas podem ser flexíveis, propiciando que professores com diferentes formações e experiências possam adequá-las à sua realidade de forma segura e satisfatória.

Para Axt (1991), a experimentação nos cursos de licenciatura tem por objetivo se contrapor com a chamada racionalidade técnica, pois estimula o desenvolvimento da criatividade dos licenciados propondo uma aprendizagem ativa, estimulando a produção de novas técnicas partindo do conhecimento teórico para a prática de ensinar. Contribui, dessa forma, para uma fundamentação e análise do futuro exercício da docência e também para a realização de uma leitura crítica das práticas nas quais estão sendo formados. Vindo de encontro com as ideias de Maldaner (2013), ressalta-se que essa proposta não está voltada para a formação de cientistas como ocorreu nas décadas de setenta/oitenta, pois envolve a formação da cidadania através da contextualização do tema social na prática experimental. A observação dos resultados e dos produtos do trabalho são fatores que os professores observam como reconhecimento do seu sucesso no trabalho realizado.

No trabalho de Perez e Aleixandre (2014), busca-se analisar os desafios impostos em uma atividade investigativa no laboratório sobre "como evitar o escurecimento das maçãs cortadas?", que visa trabalhar o conhecimento teórico relevante ao contexto, transformando-o em decisões e ações práticas, além de examinar o apoio oferecido aos alunos pelo professor. Para isso a atividade pode ser executada como um problema real. Aleixandre (2010) caracteriza atividades investigativas como aquelas que consistem em problemas, não perguntas retóricas com uma solução óbvia, e são percebidas como relevantes para a vida dos alunos, possuem possibilidades de várias respostas ou caminhos experimentais e exigem que os alunos participem de práticas científicas. Segundo Queiroz e Almeida (2004), a experimentação deve integrar uma estrutura funcional entre o teórico e prático através de modelos simples que expliquem uma variedade de conceitos e que possam servir de subsídios para que o aluno possa explicar situações de laboratório ou do cotidiano.

Conforme conclusões de Perez e Aleixandre (2014), após a atividade percebe-se que o professor precisa se preparar através de grupos de estudo com outros professores ou através de atividades desenvolvidas em sala de aula que possam oferecer oportunidades para o professor refletir sobre as questões abordadas. O professor, nesse contexto, assume a postura que, segundo Carvalho e Gil-Pérez (2011), assemelha-se ao papel de um pesquisador mais experiente, orientando pesquisadores iniciantes. Isso significa que assumir o ensino por investigação como abordagem no contexto da educação científica requer do docente uma 
nova profissionalidade considerando que os professores compartilham a responsabilidade de aprender e colaborar com a construção do conhecimento, assim, deixam de ser os únicos a trabalhar com o conhecimento e os estudantes deixam de desempenhar papéis passivos de meros receptores de informação (SÁ et al., 2007). Diante do exposto, sinaliza-se para a necessidade de os professores do Ensino de Ciências ressignificarem suas concepções sobre a docência.

Edelsztein e Galagovsky (2019) descrevem uma experiência desenvolvida em quatro oficinas presenciais de três horas cada, com um total de 87 professores pertencentes à área das Ciências da Natureza e Matemática, sobre "sentidos químicos", buscando promover a reflexão sobre conhecimentos prévios, total ou parcialmente incorretos, para transformá-los em conceitos adequados. É consenso entre educadores (SANTOS, 2012; MESSEDER NETO; PINHEIRO; ROQUE 2013; BELLUCO; CARVALHO, 2014 entre outros) que todo sujeito quando chega à escola traz consigo uma compreensão do mundo que o cerca. São conhecimentos adquiridos no meio em que vive, denominados de conhecimentos prévios que, geralmente, não estão em sintonia com aqueles produzidos pela ciência. Os conhecimentos prévios, também chamados de concepções alternativas ou senso comum, se não forem adequadamente problematizados, podem interferir no processo de aprendizagem do aluno, dificultando a apropriação do conhecimento sistematizado.

Para Edelsztein e Galagovsky (2019), a atividade mostrou-se bem-sucedida, pois levaram em consideração a importância de tomar consciência de seus próprios erros, de sentir dúvidas e expressá-las, sem ser reprimido, a possibilidade de formular o conceito através da discussão e opinião do grupo, o valor de aprender com o erro modificando ideias anteriores, o poder de tomar consciência de seus conflitos cognitivos para poder resolvê-los e, por fim, o poder da motivação. Observa-se que tais experiências fazem com que os professores possam tornar-se ativos, reflexivos e motivados para aprender e ensinar, potencializando sua prática educativa cotidiana e ao mesmo tempo conseguindo estimular os alunos para se engajarem na aprendizagem.

Rial et al. (2019) apresentam em seu artigo a possibilidade do uso de ferramentas digitais online para o desenvolvimento de experimentações contextualizadas, contribuindo, dessa forma, para o desenvolvimento de competências científicas e formulação de propostas para melhorar o currículo. Foi desenvolvido um experimento sobre a Acidez do Oceano: diminuição do $\mathrm{pH}$ da água do mar, utilizando-se recursos que faça com que os professores, na formação inicial, expandam seus conhecimentos sobre $\mathrm{pH}$, bem como o modo de intervenção na sala de aula, onde no final se aponta limitações ao uso desses recursos didáticos digitais por parte dos professores. Por isso é necessário que a formação inicial contribua para o desenvolvimento de habilidades específicas científicas (ALVAREZ et al., 2013), uma vez que os futuros professores não poderão ensinar o que não sabem.

Em outra análise, Mordeglia e Mengascini (2014) trazem outras limitações que podem estar ligadas às práticas experimentais na formação de professores como: a) origem institucional: ausência de laboratórios, falta de recursos e materiais, dificuldades organizacionais e ausência de tradição institucional; b) limitação dos professores: histórico da formação, ainda do modelo de ensino transmissão-recepção; c) limitações de origem curricular: a quantidade e diversidade de conteúdos; d) limitações contextuais: desvalorização social do 
conhecimento científico. Como exemplo, tem-se os desafios inerentes ao Ensino de Química. Em uma realidade marcada pela diversidade de contextos, sujeitos e problemas sociais, é exigido do professor a capacidade de inovar a sua prática, solucionar os problemas que se impõem e tomar decisões fundamentadas. Nesse cenário, torna-se um imperativo assumir a aproximação com pesquisa em ensino e a prática reflexiva como estratégias e objetivos da formação docente (CARVALHO; GIL-PÉREZ, 2011; MALDANER, 2013).

Outra questão tem sido as discussões sobre os currículos escolares do Ensino de Ciências, isso porque esses programas curriculares de ensino não estão levando em consideração as atuais expectativas e necessidades dos estudantes da Educação Básica e nem da preparação de seus professores, como mostram pesquisas educacionais (MALDANER; ZANON, 2004; MORAES, 2008) e avaliações públicas da qualidade da Educação Básica brasileira.

Com relação às metodologias na investigação, Molina, Jaime e Berzosa (2012) afirmam que são os problemas que devem guiar a metodologia e não vice-versa. Assim, não se deve optar por um ou outro método, mas selecioná-lo com base na natureza do problema e o tipo de concepção que se pretende chegar, pois, para Monteiro et al. (2017), contrapondo-se à prática de atividades experimentais conservadoras, que visam apenas comprovar teorias, é que se propõem atividades experimentais investigativas. Nesse tipo de abordagem, o aluno é levado a resolver problemas, partindo de conhecimentos que possui sobre o assunto. Tais atividades podem ser utilizadas como orientação, de forma a dar suporte para os estudantes pesquisarem problemas oriundos do seu cotidiano. Nesse contexto, a educação científica valoriza o entendimento dos conteúdos, dos valores culturais, da tomada de decisões relativas ao cotidiano e à resolução de problemas. Buscar-se-á, com atividades investigativas, despertar no aluno o gosto pela ciência, estimulando a curiosidade e a busca do conhecimento pela investigação. Entende-se que, dessa forma, os alunos poderão desenvolver as competências necessárias para resolver os problemas que lhe aparecerem no seu dia a dia. Para Suart (2014, p. 74) "[...] as atividades experimentais investigativas partem de uma situação problema, de interesse do aluno, a fim de que este se motive e veja necessidade em aprender o conteúdo a ser desenvolvido."

Para Ferreira, Corrêa e Silva (2019), os alunos podem compreender os conceitos científicos de uma forma mais efetiva e passam a conhecer melhor sobre a natureza da ciência quando se envolvem em uma abordagem investigativa. Diante dessa perspectiva, a experimentação pode ser um momento rico para atingir essa finalidade. A construção do conhecimento científico se dá pela investigação, o que se leva a concordar com Sasseron e Machado (2017, p. 16) uma vez que "a investigação torna-se importante em sala de aula, pois por meio dela criam-se oportunidades para que os alunos entrem em contato com elementos da cultura científica". Isso leva a sugerir a ampla discussão dos objetivos da experimentação na Educação Básica, tanto nos cursos de formação inicial quanto nos de formação continuada.

\section{Experimentação Investigativa na Educação Básica}

A Experimentação Investigativa na Educação Básica foi tratada nos artigos analisados, dos 83 artigos, 11 se relacionam a esta temática. As análises são baseadas em intervenções de experimentação investigativa implementadas em turmas de alunos da Educa- 
ção Básica, visando um melhor entendimento dos conteúdos que se referem ao Ensino de Ciências (MOLINA et al., 2011, TORRES et al., 2012, CASAL, 2013, SENRA; BRAGA, 2014, PÉREZ, 2015, TOLEDO; FERREIRA, 2016, RODRÍGUEZ; PÉREZ, 2016, FRIGGI; CHITOLINA, 2018, GARCIA-MARTÍNEZ et al., 2018, MORI; CURVELO, 2018, MOURA et al., 2019).

Estudos relacionados ao Ensino de Ciências apontam vários problemas que podem estar gerando dificuldades nos processos de ensino e aprendizagem, entre eles destaca-se a falta de contextualização. Segundo Silva (2005), o Ensino de Ciências está cada vez mais descontextualizado e mais distante da necessidade do aluno. Muitas críticas ao ensino tradicional referem-se à ação passiva do aprendiz que, frequentemente, é tratado como mero ouvinte das informações que o professor expõe. Tais informações, quase sempre, não se relacionam aos conhecimentos prévios que os estudantes construíram ao longo de suas vidas (GUIMARÃES, 2009). Para Ferreira (2011), a forma com que se trabalha ciência na escola não auxilia os alunos a compreenderem o mundo. Ao contrário, está alheia à realidade do cotidiano. A área de Ciências da Natureza possibilita aos estudantes compreender conceitos fundamentais e estruturas explicativas da área, analisar características, fenômenos e processos relativos ao mundo natural e tecnológico, além dos cuidados pessoais e o compromisso com a sustentabilidade e a defesa do ambiente. A respeito disso, a Base Nacional Comum Curricular (BNCC) declara que:

\footnotetext{
[...] As análises, investigações, comparações e avaliações contempladas nas competências e habilidades da área podem ser desencadeadoras de atividades envolvendo procedimentos de investigação. Propõe-se que os estudantes do Ensino Médio ampliem tais procedimentos, introduzidos no Ensino Fundamental, explorando, sobretudo, experimentações e análises qualitativas e quantitativas de situações-problema. (BRASIL, 2017, p. 551).
}

Sendo assim, a experimentação apresenta-se como alternativa metodológica para a contextualização no Ensino de Ciências, permitindo que o aluno estabeleça relação entre teoria e prática. Giordan (2009) afirma que tanto alunos quanto professores veem a experimentação como uma metodologia que tem potencial e que promove, além da interação dos alunos na sala de aula, uma aprendizagem significativa. Atividades experimentais investigativas colocam o aluno como protagonista da sua própria aprendizagem, pois a característica dessa atividade é colocar o aluno participante do processo, investigando, interpretando, buscando soluções e desenvolvendo hipóteses. Cumprindo, desta forma, o verdadeiro sentido do Ensino de Ciências.

Pérez (2015) traz em seu artigo o estudo para o desenvolvimento de competências científicas em estudantes através da participação dos mesmos em práticas científicas com a implementação de pesquisas investigativas, com análise e interpretação de dados, durante uma experimentação em laboratório. Como resultado, observa-se uma evolução dos alunos, já que no final do estudo eles são capazes de elaborar projetos que permitem resolver a tarefa sem a ajuda do professor. Também há progresso na prática e análise de interpretação de dados, tornando o aluno responsável pelo processo de resolução de suas tarefas e de sua participação em práticas científicas. Considera-se também importante o planejamento das 
atividades investigativas antes de sua implementação, uma vez que permite que os alunos realizem um número maior de práticas epistêmicas. Para Silva (2008), por meio das práticas epistêmicas, a comunidade cientifica é entendida como um espaço de elaboração e negociação de saberes e de valores que qualificam o que pode ser considerado como boas questões, métodos e respostas adequadas. Nesse sentido, pode-se considerar que a aprendizagem científica é uma atividade epistêmica na qual são relevantes os critérios acerca de que conhecimento pode ser considerado como aceitável dentro de um determinado marco disciplinar (JIMÉNEZ ALEIXANDRE, 2006, KELLY, 2005). O processo de apropriação das práticas sociais da ciência em ambiente escolar deve favorecer a participação de uma nova comunidade de discurso, de uma nova cultura (DRIVER et al, 1999), em que aspectos epistêmicos sejam promovidos e valorizados e, com isso, sejam aprendidas as práticas discursivas similares às da comunidade científica (ARAÚJO, 2008).

Pérez (2015) ainda propõe em seus estudos que, para melhorar a qualidade dos projetos experimentais realizados pelos alunos, é necessário suportes de ensino e a necessidade de introduzir regularmente tarefas de laboratório que permitam a participação dos alunos nas práticas científicas, uma vez que as mesmas permitem desenvolver a competência investigativa. Para Azevedo (2004), Gonçalves e Goi (2018), a utilização de atividades investigativas pode conduzir o aluno a refletir, discutir, explicar, relatar e não apenas ficar restrito ao favorecimento de manipulação de objetos e a observação de fenômenos. Pérez (2015) ressalta que, sabendo que tais atividades apresentem dificuldades não só para os alunos, mas também para os professores, eles precisam ser preparados em como promover a participação efetiva do aluno. Assim, para Nóvoa (1997, p. 26), “a troca de experiências e a partilha de saberes consolidam espaços de formação mútua, nos quais cada professor é chamado a desempenhar simultaneamente, o papel de formador e de formando".

Para Molina et al. (2011) o projeto de pesquisa é uma metodologia recente, mas muito importante para o Ensino de Ciências. Em sua pesquisa, busca-se contribuir para a disseminação, bem como promover a reflexão e discussão sobre essa metodologia no Ensino de Ciências. Seguindo as intencionalidades percebidas na pedagogia de projetos, é possível estabelecer relações entre a Experimentação Investigativa e os primórdios da inserção da pesquisa na sala de aula. Dewey (1960) salienta que os projetos não precisavam, necessariamente, seguir uma série de passos definidos, mas havia etapas necessárias em cada ato de pensamento integral: recolher os dados de um problema ou fatos de uma dada situação; observar e examinar esses fatos; elaborar hipóteses ou soluções possíveis, escolhendo a que melhor se encaixa no contexto. Por fim, verificava-se a ideia elaborada pela sua aplicação em outras observações ou novas experiências, podendo começar por qualquer uma das etapas e voltar atrás quando necessário (LOURENÇO FILHO, 1978).

Molina et al. (2011) ainda destacam que um dos recursos para o projeto de pesquisa são os ambientes de aprendizagens (salas de aula, laboratórios, ambientes abertos), pois é necessário coletar registros de todo o processo como o que alunos, professores e pesquisadores aprendem ao longo do experimento, sendo uma das principais características a ruptura da diferença entre professor e pesquisador. Sendo que, tanto aluno, professor quanto pesquisador se tornam parte integrante do sistema que está sendo investigado, interagindo e levando a relacionamentos complexos que quebram a distinção entre os mesmos. Isso os 
leva a gerar hipóteses durante o experimento ou abandonar ou reformular novas hipóteses. Na perspectiva de Maturana e Varela (2005), tanto o professor quanto os estudantes, ao experienciarem o ensinar e o aprender em um espaço em que todos participam, se envolvem, trazem contribuições relevantes e sofrem perturbações mútuas que desencadeiam mudanças de estado em ambos. Os estudantes se dão conta dessa realidade ao relatar que os professores também aprenderam com os alunos. Aprender é o resultado da própria transformação na convivência, aprendemos porque nos colocamos com o outro, legitimamos o saber do outro ao mesmo tempo em que o outro também legitima o nosso.

Casal (2012) descreve e analisa em seu trabalho uma sequência didática composta por três trabalhos práticos de laboratório em formato de pesquisa. Em cada um dos trabalhos práticos a participação dos alunos foi aumentando, assim como a produção de artigos científicos baseados na pesquisa, além da compreensão da natureza da ciência e de suas habilidades científicas. Demonstra, dessa forma, que a sequência didática pode melhorar as habilidades científicas do aluno, bem como os objetivos e hipóteses e que a mesma deve incluir: perguntas a serem pesquisadas, priorizar a observação, analisar a observação, formular uma explicação baseada na informação, conectar a informação com os modelos e conhecimentos científicos, comunicar e justificar a explicação e, por último, reflitir sobre o processo. Segundo Zabala (1998, p.18) sequências didáticas são: “[...] um conjunto de atividades ordenadas, estruturadas e articuladas para a realização de certos objetivos educacionais, que têm um princípio e um fim conhecidos tanto pelos professores como pelos alunos [...]".

Conforme preceitua Brasil (2012), as sequências são uma ferramenta importante para a construção do conhecimento. Ao organizar a sequência didática, o professor poderá incluir atividades diversas como leitura, pesquisa individual ou coletiva, aula dialogada, produções textuais, aulas práticas, etc. A sequência de atividades visa trabalhar um conteúdo específico, um tema ou um gênero textual da exploração inicial até a formação de um conceito, uma ideia, uma elaboração prática, uma produção escrita (BRASIL, 2012, p. 21).

Moura et al. (2019) tratam em seu artigo de uma sequência didática desenvolvida em uma escola que possui um projeto de horta escolar, usando o processo hidropônico para aplicação das aulas, as quais contemplaram os aspectos qualitativos e quantitativos no preparo das soluções nutritivas utilizadas nesse processo. Para Brandão (2012), os conhecimentos construídos por meio desses projetos podem ser socializados na escola e transportados para a vida familiar do educando.

Ainda no contexto da sequência didática investigativa, Ferraz e Sasseron (2017) defendem a importância das interações entre estudantes, com foco na promoção da argumentação, para a construção do conhecimento. Segundo os autores, a abordagem investigativa proporciona um ambiente em que a construção de argumentos é favorecida pela interação e colaboração entre os membros e elementos que constituem a sala de aula. Além disso, eles consideram que o ensino por investigação se caracteriza por favorecer o trabalho integrado com diferentes práticas metodológicas e didáticas, sendo que estas variam de acordo com o perfil do professor e os recursos disponíveis para o desenvolvimento de uma aula (FERRAZ; SASSERON, 2017). Dessa forma, ainda usando as ideias de Ferraz e Sasseron (2017), o ensino por investigação pode ocorrer por meio de ações e estratégias diferenciadas para que professores e alunos possam interagir e colaborar entre si e para que 
a compreensão dos diferentes temas seja estruturada, ampliada e aprofundada (FERRAZ; SASSERON, 2017).

Senra e Braga (2014) abordam uma rede de aprendizagem criada no Centro Federal de Educação Tecnológica Celso Suckow da Fonseca - Rio de Janeiro - CEFET/RJ, formada por pequenos grupos de alunos, que foram denominadas Células de Inovação. Nesses grupos, os alunos eram envolvidos em problemas reais, discutiam sobre eles e buscavam desenvolver soluções para os mesmos. Cada célula tinha a orientação de um professor externo, diferente daquele que ministrava as aulas formais. Esse professor tinha o papel de dinamizar discussões e coordenar o desenvolvimento do projeto com os alunos. O papel desse professor não era de apresentar algo pronto, uma receita a ser seguida, mas orientá-los a investigar, alimentando-lhes a curiosidade e incentivando a busca de respostas (MARTINS, 2009, MOREIRA, 1998).

Segundo Senra e Braga (2014), a ideia central seria problematizar o processo de construção do conhecimento científico a partir do envolvimento dos estudantes num processo de investigação e discussões sobre a prática científica inserida no contexto social. Nesse caso, a natureza da Ciência seria tratada a partir de uma dupla abordagem, tanto implícita (investigação) como explícita (discussão sobre). O projeto proposto aos alunos foi o da construção de um coletor solar para aquecimento de água, utilizando materiais descartáveis com baixo poder de reciclagem, pois, se por um lado os avanços científicos e tecnológicos trouxeram progresso e melhoria para a qualidade de vida de boa parte da humanidade, por outro esses mesmos avanços também provocaram, e vem provocando, destruição da natureza por influenciar o consumismo desenfreado de bens não duráveis que, por sua vez, aumenta a produção de lixo e extração de recursos naturais, inclusive aqueles considerados não renováveis (PINOTT, 2010).

Conforme Senra e Braga (2014), cada encontro foi desenvolvido a partir de uma sequência única, começava-se com um debate prévio (problematização), sendo que trabalho com projetos de pesquisa mostrou-se eficiente dentro do grupo que aceitou tomar parte desse processo. Moran (2011, p. 34) afirma que "a metodologia de projetos de aprendizagem é a única compatível com uma visão de educação e de aprendizagem que encare o aluno como protagonista, como parte da solução e não do problema".

Rodrigéz e Pérez (2016) também abordam os resultados de uma pesquisa relacionada à implementação de uma sequência didática com atividades investigativas que busca analisar o desempenho dos alunos através de respostas em relatórios escritos, bem como suas evoluções em cada tarefa, ou seja, suas evoluções de conhecimento adquirido e o desenvolvimento gradual de habilidades, tais como: identificação das questões abordadas, conceitos que orientam a pesquisa científica, implementação da pesquisa, reconhecimento e análises de explicações e modelos e a comunicação de argumentos científicos. Quando as atividades são formuladas adequadamente, elas permitem que os alunos entendam melhor o funcionamento da Ciência, o que contribui para o desenvolvimento da competência científica, bem como atinge os objetivos do currículo (CRUJEIRAS; JIMÉNEZ, 2012). Para isso, é necessário fornecer aos alunos alguma orientação para a resolução adequada destes tipos de tarefas, e gradualmente, conseguir que elas possam ser concluídas e realizadas de forma autônoma (CRUJEIRAS; JIMÉNEZ, 2015). Para potencializar a discussão acerca do papel 
do professor nessa perspectiva, convém mencionar os ideais de Moran (2015), segundo o qual o professor que se utiliza do método ativo tem o papel de curador e de orientador:

\begin{abstract}
Curador, que escolhe o que é relevante entre tanta informação disponível e ajuda a que os alunos encontrem sentido no mosaico de materiais e atividades disponíveis. Curador, no sentido também de cuidador: ele cuida de cada um, dá apoio, acolhe, estimula, valoriza, orienta e inspira. Orienta a classe, os grupos e a cada aluno. Ele tem que ser competente intelectualmente, afetivamente e gerencialmente (gestor de aprendizagens múltiplas e complexas). Isso exige profissionais melhor preparados, remunerados, valorizados. Infelizmente não é o que acontece na maioria das instituições educacionais (MORAN, 2015, p. 24).
\end{abstract}

Ainda, segundo Moran (2015), é importante conhecer os alunos, sua realidade, suas expectativas, seus sonhos, para poder aproximar as atividades previstas com os interesses deles. Conhecê-los e acolhê-los, olhá-los nos olhos, mostrar-lhes simpatia, valorizar o que fazem bem.

Para Torres et al. (2012), a aprendizagem não se caracteriza em responder perguntas, mas em fazer perguntas com precisão e originalidade, as quais são essenciais para construir novos conhecimentos. No entanto, os alunos fazem um número muito pequeno de perguntas no dia a dia da sala de aula. Fatores como a autoestima, o medo do ridículo, como acontece com os alunos de baixo desempenho, e outros como o medo de não corresponder às expectativas, são fatores que dificultam a expressão de perguntas. Segundo Moraes (2000), a atitude questionadora está diretamente relacionada com a atitude pesquisadora, estabelecendo-se uma relação de partida e contrapartida, de pergunta e de informação, cada resposta podendo ser um questionamento que, se devidamente elaborado pelo professor, passa a constituir um verdadeiro desafio ao aluno. A ausência de questionamento é concebida, muitas vezes, como um obstáculo na construção do saber e sua presença aparece como um dos aspectos positivos, tanto na ação do professor como na dos alunos (COELHO; KOHL; DI BERNARDO, 2002). Giordan e Vecchi (1996) consideram essenciais, portanto, criar situações científicas perturbadoras caso se deseje ir mais adiante à construção do saber. Para esses autores, é por meio de questionamentos que o aluno seleciona as informações que apreende. Essa atividade cria uma filtragem da realidade; por meio dela é que o discente extrai as informações que aprende (GIORDAN; VECCHI, 1996).

Para isso, os conhecimentos prévios são fundamentais na construção de novos significados, portanto pode-se admitir que diante de um novo conteúdo o aluno elabora uma representação, utilizando os conhecimentos prévios que lhe permitam atribuir a esse conteúdo algum grau de significado. Zabala (1998) afirma que para poder estabelecer vínculos entre os novos conteúdos e os conhecimentos prévios, é preciso determinar interesses e motivações, para gerar um ambiente em que seja possível que os alunos se abram, façam suas perguntas e comentem o processo.

Friggi e Chitolina (2018) relatam e discutem em seu trabalho o ensino do processo de separação de misturas através de situações-problema e atividades experimentais investigativas a partir das concepções prévias dos alunos. Para Ausubel (1982), esta forma de interação do conhecimento prévio com o conhecimento novo provoca uma interação na estrutura cognitiva do aluno, que ele descreve como aprendizagem significativa. Segundo 
o autor, quando o aluno relaciona um novo conhecimento a um já existente, denominado subsunçor; e dessa forma ganha significado, através de uma interação não-literal e não-arbitrária, os novos conhecimentos adquirem sentido para o sujeito e os conhecimentos prévios adquirem novos significados ou maior estabilidade cognitiva. Moreira (2006) explica que subsunçor é o nome que se dá a um conhecimento específico, existente na estrutura de conhecimentos do indivíduo, que permite dar significado a um novo conhecimento que lhe é apresentado ou por ele descoberto, seja por recepção ou por descobrimento. Assim, a atribuição de significados aos novos conhecimentos depende da existência de conhecimentos prévios especificamente relevantes e da interação com estes. Este subsunçor pré-existente pode ter maior ou menor estabilidade cognitiva, pode estar mais ou menos diferenciado, e, com isto, ser mais ou menos elaborado em termos de significados. Contudo, como o processo é interativo, quando o subsunçor servir de ideia âncora para um novo conhecimento, ele próprio se modifica adquirindo novos sentidos e interpretações.

Friggi e Chitolina (2018) afirmam que durante a realização das atividades experimentais foi possível observar importantes contribuições no ensino e na aprendizagem dos alunos. Dentre elas, pode-se citar: o caráter motivador na tentativa de despertar a atenção dos alunos; a iniciativa pessoal e a tomada de decisões no momento que os alunos foram instigados a pesquisar; propor hipóteses e fornecer explicações para realização da atividade ou nos fenômenos observados durante a realização do experimento; criatividade na construção de materiais alternativos que foram empregados no desenvolvimento dos experimentos; aprender e compreender conceitos científicos e detectar e corrigir eventuais erros conceituais antes e após a realização das atividades experimentais. Em relação às atividades experimentais desenvolvidas, mesmo havendo um espaço destinado para a realização de atividades laboratoriais na escola, a falta de materiais e equipamentos não impediu a execução das atividades propostas. Ao contrário, a elaboração dos materiais alternativos, além de estimular a criatividades dos alunos, permitiu demonstrar que é possível sim realizar atividades experimentais sem materiais e equipamentos específicos de laboratórios de química. De acordo com Silva (2009), uma vez que revistas sobre Educação em Ciências contêm, frequentemente, experimentos com materiais de baixo custo sobre diferentes temáticas que contemplam diversos conteúdos é incoerente justificar o pouco uso de atividades experimentais pela falta de recursos.

Faria (2007) defende o modelo didático de formulação de perguntas como uma estratégia para promover nos alunos uma aprendizagem mais reflexiva e, desse modo, tornar os conhecimentos prévios ativados e explícitos para o coletivo da sala de aula. Com isso não só o aluno identifica suas próprias ideias, mas também o professor que torna esses conhecimentos mais explícitos para a sala de aula, para serem negociados entre professor/aluno e aluno/aluno. Uma das funções das perguntas do professor no decorrer do discurso na sala de aula é promover nos alunos uma reflexão sobre o próprio conhecimento. Esse processo reflexivo sobre o próprio conhecimento costuma ser chamado de metacognição. De acordo com Vygotsky (1989, apud LORENCINI JR, 2000, p. 47-48), "os conceitos cotidianos são extraídos geralmente da busca de regularidades e constantes no comportamento dos objetos, os conceitos científicos são, na verdade, o produto da reflexão que fazemos sobre nossas ideias a respeito do comportamento dos objetos". É relevante o papel do professor 
como mediador na aprendizagem e na ajuda da metacognição, pois por meio das perguntas ocorre maior elaboração cognitiva dos conceitos científicos.

García-Martínez et al. (2018) destacam, em sua pesquisa, uma proposta didática inovadora relacionada às transformações de matéria e energia, baseada em uma atividade diária realizada na cozinha. A preparação de alimentos, tendo como objetivo aproximar a ciência do ambiente cotidiano do aluno, além de promover a igualdade de gênero, coloca lado a lado meninos e meninas na atividade Ato de Cozinhar. Para Pinto Cañon (2004) e García-Martínez et al. (2018), a abordagem da ciência para a vida cotidiana mostra ao aluno o alto grau de envolvimento no ambiente e facilita seu aprendizado através do uso de exemplos ou tarefas familiares. Esta relação entre ciência e vida cotidiana com a finalidade de responder às necessidades e interesses do aluno é o que Caamano (2011) chama de contextualização da Ciência, a qual dá sentido a conceitos, promovendo a motivação e a aprendizagem extensiva que envolve aspectos cognitivos. Para Varela e Souza (2018), o conhecimento da Química Experimental se torna uma realidade próxima se o professor tem a concepção de que a aprendizagem de química pode acontecer em diversos lugares, enfatizando a cozinha, pois o conhecimento de química se torna melhor quando se une teoria e prática. Já Bernadelli (2004), refere que a relação de parceria dos professores e alunos precisa ser mantida para que o aprendizado mútuo venha a acontecer e o encanto na ministração dos conteúdos precisa ser feito com criatividade, de forma intuitiva, otimista e feliz, o que faz com que os alunos assimilem com mais facilidade. Oliveira (2010) entende que a experimentação pode contribuir de diferentes maneiras na formação dos alunos. A primeira forma é motivá-los e chamar sua atenção para atividades propostas, conseguindo uma melhor participação dos estudantes nas aulas; viabilizar o trabalho em grupo, pois o mesmo proporciona uma melhor interação entre os alunos assim como também estimula algumas competências como a divisão de tarefas, responsabilidades com o grupo e negociação de ideias, respeitando a opinião do outro. Também ajudará fazendo com que os alunos se posicionem e tome decisões. "Quando instigados a pesquisar e propor hipóteses para a solução de problemas ou a pensar e fornecer explicações para os fenômenos observados nos experimentos, os alunos são estimulados a tomar decisões e expressar suas ideias para outras pessoas" (OLIVEIRA, 2010, p.142).

Para atingir esses fins foram utilizadas atividades práticas e o uso de tecnologias da informação e comunicação (TICs), contextualizadas no campo da culinária e realizadas em um ambiente recreativo e igualitário. Acredita-se que aulas que contemplam recursos tecnológicos são mais dinâmicas, agradáveis, atrativas e podem conquistar a atenção dos alunos. Em um mundo conectado à tecnologia é imprescindível que o professor supere seus medos e as barreiras que o impedem de utilizar esse recurso. Vivemos na era da informação e, portanto, deve-se vislumbrar uma educação para tal. E para que isso ocorra é necessário entender que: “[...] educar para a era da informação não significa apenas preparar o indivíduo para a apropriação da tecnologia e sua aplicação para melhorar o ensino (MORAES, 1997, p. 23)".

Nesse contexto, concorda-se com o posicionamento de Moraes (1997) e García-Martínez et al. (2018), pois para que a educação na era da informação aconteça tanto professores quanto alunos deverão se propor a novas formas de ensinar e aprender e a procurar novos meios para que isso se concretize. 
O trabalho de Toledo e Ferreira (2016) se propôs em demonstrar como é possível elaborar e testar modelos experimentais evitando erros básicos, os experimentos utilizados como modelo pretendiam simular o efeito estufa. Esse assunto foi escolhido porque, apesar de estar constantemente presente nas discussões, tanto na mídia quanto no sistema de ensino, não faz parte da ciência normal segundo os pressupostos de Kuhn (1998), já que devido a suas controvérsias não há uma concordância da comunidade acadêmica e, portanto, é importante para a discussão da atividade investigativa. Para que esses modelos sejam testados, é preciso superar a visão reducionista da experimentação de que as hipóteses podem ser testadas e provadas através da verificação, pois isso leva a uma visão simplista e absoluta da natureza das hipóteses científicas e da teoria da atividade experimental, contribuindo para que os estudantes tenham uma visão deturpada da Ciência e do conhecimento científico como se este estivesse na natureza pronto para ser descoberto (CACHAPUZ et al., 2005). Pois, para Toledo e Ferreira (2016), quando o experimentador, ingênuo, na primeira execução do experimento obtém dados que corroborem suas hipóteses, ele se sente satisfeito e finaliza sua investigação. Esse comportamento é equivocado, pois um bom modelo não deve apenas reproduzir o desejado, mas também resistir a testes. Assim, a situação ideal é que o experimentador repita o procedimento garantindo a reprodutibilidade e teste sua hipótese variando os parâmetros pertinentes.

Para tanto, Toledo e Ferreira (2016) descrevem os princípios básicos gerais para se elaborar um modelo experimental consistente, seja do efeito estufa ou outro qualquer. Inicia-se com uma situação problema, portanto o primeiro passo é realizar uma pergunta. Em vez de solicitar que os alunos simulem o efeito estufa, o professor deveria elaborar uma questão em posse dos conhecimentos teóricos mínimos necessários; o segundo passo é a elaboração da hipótese ou hipóteses. O terceiro passo é o teste da hipótese. Porém, para testá-la, é preciso planejar a forma de se chegar aos dados e quais os tipos de dados que se pretende obter, como, por exemplo, temperatura, concentração, $\mathrm{pH}$, pois caso haja falha neste momento os resultados podem não ter utilidade alguma para o objetivo visado. O planejamento da coleta de dados inicia-se com novas perguntas, pois a hipótese inicial, apesar de nortear o sistema, não dispensa questões capazes de delimitar o aparato experimental. Posteriormente, desenha-se a estrutura do experimento a ser realizado, levantando suas variáveis e decidindo o tipo de dado que se pretende mensurar. Assim, por meio do conjunto de variáveis, são determinadas aquelas explícitas do sistema. Nesse ponto, inicia-se a montagem do experimento com posterior coleta de dados e, então, com os dados em mãos é possível ainda chegar a duas situações: 1) dados corroboram com a hipótese; 2) dados discordam da hipótese.

Quando os dados discordam da hipótese, o experimentador se vê diante de dois caminhos. O primeiro consiste em reformular sua hipótese podendo considerá-la falsa e o segundo consiste em submeter a teste seu arranjo experimental, verificando se as variáveis e todo o aparato utilizado são adequados a proposta visada.

Assim, esses são os princípios básicos gerais para se elaborar um modelo experimental consistente. Não os levar em consideração pode implicar em premissas falsas que consequentemente levarão a resultados equivocados.

Ainda reforçando as ideias de Toledo e Ferreira (2016) a literatura indica que experimentos de natureza investigativos são mais bem-sucedidos, pois esta abordagem não ape- 
nas se qualifica como motivadora, mas está correlacionada com um ganho em habilidades cognitivas de alta ordem (SUART, 2008). Goi e Santos (2008) argumentam que o uso de atividades investigativas resultou em uma melhora na comunicação dos alunos que, muitas vezes durante as aulas eram alunos que não participavam efetivamente das discussões.

Mori e Curvelo (2018) fazem um estudo sobre os compromissos teóricos da Experimentoteca com o ensino por investigação e como estes são acompanhados de esforços práticos por parte de seus idealizadores e seus usuários, visando a realização desse tipo de atividades experimentais. A Experimentoteca é um projeto desenvolvido pelo Centro de Divulgação Científica e Cultural (CDCC-USP), que busca prover às escolas da Educação Básica com materiais para o ensino experimental. Atualmente encontra-se disseminada para mais de 30 universidades, museus e centros de ciências nas cinco regiões do Brasil. Desempenha um importante papel no desenvolvimento do ensino por investigação, pois, segundo Guimarães (2009), a experimentação pode ser uma estratégia eficiente para a criação dos problemas reais que permitam a contextualização e o estímulo de questionamentos de investigação.

A inserção de atividades experimentais investigativas no Ensino de Ciências, da Educação Básica, mostrou-se uma estratégia eficiente no processo de aprendizagem dos alunos, constata-se isso por meio da análise de literatura dos artigos citados. Percebe-se que os alunos envolvidos são colocados em situação de realizar pequenas pesquisas, combinando simultaneamente conteúdos conceituais, procedimentais e atitudinais.

\section{CONSIDERAÇões FINAIS}

A revisão de literatura realizada em artigos acadêmicos sobre a temática Experimentação no Ensino de Ciências, publicados em periódicos da classificação Qualis Capes A1, A2 e B1, no período de 2010 a 2019, permitiu investigar e categorizar a natureza dos trabalhos apresentados, tornando possível considerar a Experimentação Investigativa no ponto de vista construtivista, que entende a ciência como uma atividade humana dependente do contexto, uma temática ainda pouco difundida no Ensino de Ciências no Brasil em virtude do pequeno número de trabalhos identificados nos periódicos brasileiros. Observa-se que na Espanha essa temática é mais abordada já que dos 22 artigos analisados, 14 eram do periódico Enseñanza de las Ciencias, da Espanha, escritos, na maioria por estudiosos espanhóis que desenvolvem atividades e experimentos investigativos. Justificando assim, o que a literatura já aponta, relativo aos contextos políticos vivenciados em determinados períodos, onde tendências positivistas e progressistas determinam a forma de investigação no Ensino de Ciências.

Ao analisar a categoria de Experimentação Investigativa na formação inicial e continuada de professores, mesmo sabendo que ainda é pouco difundida nos cursos de licenciatura e durante a formação continuada, pode-se destacar que há uma tendência por parte de grupos de professores no meio acadêmico em investir nessa abordagem. Eles o fazem pelas aulas, grupos de estudo, participação em Programas da Capes como Programa Institucional de Bolsa de Iniciação à Docência-PIBID e o Programa Residência Pedagógica, produção de artigos e em cursos de formação com professores da Educação Básica. Isso faz com que o EI seja uma 
estratégia didática em que os professores deixam de simplesmente fornecer conhecimentos aos alunos, que passam a ser mais ativos, e não meros receptores de informações.

No que se refere à análise Experimentação Investigativa na Educação Básica, pode-se verificar que é uma metodologia que está sendo implementada. O ensino com base na investigação possibilita o aprimoramento do raciocínio e das habilidades cognitivas dos alunos, e também a cooperação entre eles, além de possibilitar que compreendam a natureza do trabalho científico. Pois, para Ferreira e Goi (2018, p. 26), à medida que o professor promove a interação discursiva com os alunos, estes vão tomando consciência do processo de construção do conhecimento científico por meio de sua reflexão.

Para tanto, a partir da revisão de literatura realizada, espera-se que a Experimentação Investigativa seja uma estratégia metodológica presente no Ensino de Ciências, uma vez que a mesma desenvolve as potencialidades investigativas dos alunos, promovendo uma educação científica voltada ao desenvolvimento cognitivo, social e da autonomia na construção de seu conhecimento. Por fim, possibilitando-lhe uma leitura mais elaborada da realidade por meio do Ensino de Ciências.

\section{REFERÊNCIAS}

ALEIXANDRE, M. P. J. 10 Ideas Clave. Competencias em argumentación y uso de pruebas. Barcelona: Graó, 2010.

ALVAREZ, L. M. M., ARIAS C.A., PÉREZ, R. U.;SERRALLÉ , M. J. F. La historia de lãs ciências em eldesarrollo de competências científicas. Enseñanza de las Ciencias: Revista de investigación y experiências didácticas. v.31. n. 1. p. 213-233, 2013.

ARAÚJO, A. O. O uso do tempo e das práticas epistêmicas em aulas práticas de química. 141f. Dissertação (mestrado em Educação) Faculdade de Educação - UFMG, Minas Gerais.2008.

AUSUBEL, D. P. A aprendizagem significativa: a teoria de David Ausubel. São Paulo: Moraes. 1982.

AXT, R. O papel da experimentação no ensino de ciências. Tópicos em ensino de ciências. Porto Alegre: Editora Sagra, 1991.

AZEVEDO, M. C. P. S. Ensino por Investigação: Problematizando as atividades em sala de aula. In: Carvalho, A. M. P. (org.). Ensino de Ciências: Unindo a Pesquisa e a Prática. São Paulo: Thomson, cap. 2, p. 19-33, 2004.

BARDIN, L. Análise de Conteúdo. São Paulo: Edições 70, 2011.

BELLUCO, A.; CARVALHO, A. M. P. Uma proposta de sequência de ensino investigativa sobre quantidade de movimento, sua conservação e as leis de Newton. Caderno Brasileiro de Ensino de Física, v. 31, n. 1, p. 30-59, abr. 2014. 
BERNADELLI, M.S. Encantar para ensinar - um procedimento alternativo para o ensino de química. In: Convenção Brasil Latino América, Congresso Brasileiro e Encontro Paranaense de Psicoterapias Corporais. 1., 4., 9., Foz do Iguaçu. Anais[...] Centro Reichiano, 2004. CD-ROM. [ISBN - 85-87691-12-0]

BRANDÃO, G. K. L. Horta escolar como espaço didático para a educação em ciências. Dissertação de Mestrado apresentada ao Programa de Pós-Graduação em Mestrado Profissional em Ensino de Ciências e Matemática, da Universidade Federal do Ceará. Fortaleza- CE, 2012.

BRASIL. Base Nacional Comum Curricular (BNCC). Educação é a Base. Brasília, MEC/CONSED/UNDIME, 2018. Disponível em: http://basenacionalcomum.mec.gov.br/ images/BNCC_EI_EF_110518_versaofinal_site.pdf. Acesso em: 06 maio. 2020.

BRASIL. Base Nacional Comum Curricular (BNCC). Educação é a Base. Brasília, MEC/CONSED/UNDIME, 2017. Disponível em: $<568$ http://basenacionalcomum.mec. gov.br/images/BNCC_publicacao.pdf $>$. Acessado 09 maio 2020.

BRASIL. Secretaria de Educação Básica. Diretoria de Apoio à Gestão Educacional. Pacto nacional pela alfabetização na idade certa: alfabetização em foco: projetos didáticos e sequências didáticas em diálogo com os diferentes componentes curriculares: ano 03 unidades 06 / Ministério da Educação, Secretaria de Educação Básica, Diretoria de Apoio à Gestão Educacional. - Brasília: MEC, SEB, 2012. 47 p.

BRASIL. Parecer CNE/CP n. 2/2015. Diretrizes Curriculares Nacionais para a Formação Inicial e Continuada dos Profissionais do Magistério da Educação Básica. Brasília, DF, 2015. Disponível em: http://portal.mec.gov.br/index.php?option=com docman\&view=download\&alias=17625-parecer-cne-cp-2-2015-aprovado-9-junho-2015\&category_slug=junho-2015-pdf\&Itemid=30192 . Acesso em: 04 de maio de2020.

BRITO, L. O.; FIREMAN, E. C. Ensino de ciências por investigação: uma proposta didática "para além" de conteúdos conceituais. Revista Experiências em Ensino de Ciências. v. 13 , n. 5 , p. $462-479,2018$.

BRZEZINSKI, I. Formação de profissionais da educação (1997-2002). Brasília: Ministério da Educação, Instituto Nacional de Estudos e Pesquisas Educacionais Anísio Teixeira.2006.

CAAMAÑO, A. Enseñar química mediante La contextualización, La indagación y lamodelización. Alambique: Didáctica de las Ciencias experimentales, 17(69), pp. 21-34. 2011.

CACHAPUZ, A.; GIL-PÉREZ, D.; CARVALHO, A. D.; PRAIA, J. \& VILCHES, A. A necessária renovação do ensino das ciências. São Paulo: Cortez, 2005. 
CAMPANARIO, J. M. Asalto AL castillo: ¿a qué esperamos para abordar en serio La formación didáctica de los professores universitarios de ciencias?Enseñanza de las Ciencias. v 20. n: 2.p: 315-325. 2002.

CAMPANARIO, J. M. Contra algunas concepciones y prejuicios comunes de los profesores universitários de Ciencias sobre La didáctica de las Ciencias. Enseñanza de las Ciencias, v. 21. n: 01. P: 319-328, 2003.

CAMPOS, C. CACHAPUZ, A. Imagens de ciência em manuais de química portugueses. Química nova na escola. $\mathrm{N}^{\circ}$ 6, novembro, p.23-29, 1997.

CAÑÓN, G. P. Innovación educativa de la Química mediante recursos de la vida cotidiana. Anuario Latino americano de Educación Química, 17, p. 54-58. 2004.

CARVAlHO, A. M. P.; GIL-PÉREZ, D. Formação de Professores de Ciências: tendências e inovações. 10. ed. São Paulo: Cortez Editora, 2011.

CARVALHO, A. M. P.; SASSERON, L. H. Ensino de física por investigação: Referencial teórico e as pesquisas sobre as sequências de ensino investigativas. Ensino Em Re-Vista, Uberlândia, v. 22, n. 2, p. 249-266, jul./dez.2015. Disponível em: <http://www.seer.ufu.br/ index.php/emrevista/index >>. Acesso em: 27 abril. 2020.

CARVALHO, A. M. P., VANNUCCHI, A. I., BARROS, M. A., GONÇALVES, M. E. R.; REY, R. C. Ciências no Ensino Fundamental: o conhecimento físico. São Paulo: Scipione, 2009.

CASAL, J. D. Secuencias de apertura experimental y escritura de artículos em el laboratório: um itinerário de mejora de los trabajos prácticos em el laboratório. Enseñanza de Las Ciencia. v. 31. n. 3. p. 249-262, 2012.

COELHO, S. M; KOHL, E.; DI BERNARDO, S. Formação de Professores do Ensino Médio pela Instrumentação e Pesquisa em Ciências. In: TALLER INTERNACIONAL DE DIDÁCTICA SOBRE LA FÍSICA UNIVERSITARIA, III, 2002, Matanzas, DIDACFISU 2002.

CRUJEIRAS, B. Y; JIMÉNEZ ALEIXANDRE, M. P. Participar em las prácticas científicas: aprender sobre La ciência diseñando un experimento sobre pastas de dientes. Alambique: didáctica de las ciências experimentales, 72, 12-19. 2012.

CRUJEIRAS, B. Y; JIMÉNEZ ALEIXANDRE, M. P. Desafíos planteados por lãs atividades abiertas de indagación em ellaboratorio: articulación de conocimientos teóricos y prácticos em lasprácticascientíficas.Enseñanza de las Ciencias,, v.33. n: 1. P. 63-84.2015. 
DRIVER, R.; ASOKO, H.; LEACH, J.; MORTIMER, E.; SCOTT, P. Construindo conhecimento científico na sala de aula. Química nova na Escola, n.9, p. 31-40, maio de 1999.

EDELSZTEIN, V.; GALAGOVSKY, L. Enseñanza acerca de los sentidos químicos. Indagación sobre uma experiência motivadora. Enseñanza de las Ciencia, v 37. n.1. p. 177 194. 2019.

FARIA, A. S. Z.A funcionalidade das perguntas na elaboração do conhecimento nas aulas de ciências. Disponível em:http://www.gestaoescolar.diaadia.pr.gov.br/arquivos/ File/producoes_pde/artigo_agnes_silvia_zeckel_faria.pdf. Acessado em 12 maio 2020.

FERRAZ, A. T.; SASSERON, L. H. Espaço interativo de argumentação colaborativa: condições criadas pelo professor para promover argumentação em aulas investigativas. Ensaio, v. 19, 2017. Disponível em: http:/www.scielo.br/pdf/epec/v19/1983-2117-epec-19-e2658.pdf. Acesso em 13de maio de 2020.

FERREIRA, L. N.; QUEIROZ, S. L. Artigos da revista Ciência Hoje como recurso didático no ensino de química. Química Nova (Impresso), v. 34, p. 354-360, 2011.

FERREIRA, M. V. S.; GOI, M. E. J. Contribuições das atividades experimentais investigativas no ensino de química da Educação Básica. Trabalho de Conclusão de Curso no formato de artigo apresentado como requisito parcial para obtenção do título de Licenciado em Ciências Exatas - Química. UNIPAMPA- Caçapava do Sul, 2018.

FERREIRA, S.; CORRÊA, R.; SILVA, C. S. Estudo de Roteiros de experimentos disponibilizados em repositórios virtuais por meio do ensino por investigação. Revista Ciência \& Educação. v 25, n. 4, p. 999-1017, 2019.

FRANZOLIN, F.; FEJES, M. E. Desafios Enfrentados por professores na implementação de atividades investigativas nas aulas de Ciências. Revista Ciência \& Educação. v.19, n. 2. p. 439-454, 2013.

FREIRE, P. Extensão ou comunicação? Rio de Janeiro: Paz e Terra. 1977.

FRIGGI, D. A.; CHITOLINA, M. R.O ensino de processos de separação de misturas a partir de situações-problemas e atividades experimentais investigativas. Experiências em Ensino de Ciências. v 13. n. 5. p. 388-403, 2018.

FURIÓ MÁS, C. J. La motivación de los estudiantes y la enseñanza de La Química. Uma cuestión controvertida. Educación Química, 17, 222-227. 2005.

GARCIA-MARTÍNEZ, N.; GARCIA-MARTÍNEZ, S.; ANDREO-MARTÍNEZ, P.; ALMELA, L. Ciencia em la cocina. Uma propuesta inovadora para enseñar Física y Quimica em educación secundaria. Enseñanza de las Ciencias., v. 36. n.3. p. 179-198. 2018. 
GIORDAN, A.; VECCHI, G. As Origens do Saber: das concepções dos aprendentes aos conceitos científicos. Traduzido por Bruno Charles Magne. 2. ed. Porto Alegre: Artes Médicas, 1996.

GIORDAN, M. O papel da experimentação no ensino de ciências. Química Nova na Escola, n. 10, p. 43-49, 1999.

GOI, M.E.J.; SANTOS, F. M. T. Resolução de problemas e atividades experimentais no ensino de química. Anais[...] Trabalho apresentado no XIV Encontro nacional de ensino de química, Curitiba, 2008. Disponível em: http://www.quimica.ufpr.br/eduquim/eneq2008/ resumos/R0708-1.pdf. Acesso em: 08 de set. 2020.

GONÇALVES, F. P.; MARQUES, C. A.Problematización de las atividades experimentales em laformación y La practica docente de los formadores de professores de química. Enseñanza de las Ciencias, v 31. n. 03. p. 67-86. 2013.

GONÇALVES, R. P. N.; GOI, M. E. J. Uma revisão de literatura sobre o uso da experimentação no ensino de química. Revista Comunicações. v.25, n. 3, p. 119-140. 2018.

GONÇALVES, R. P. N.; GOI, M. E. J. A experimentação investigativa no Ensino de Ciências na Educação Básica. Revista Debates em Ensino de Química, v.: 4 n. 2. p. 207-221. 2018.

GUIMARÃES, C. C. Experimentação no Ensino de Química: Caminhos e Descaminhos Rumo à Aprendizagem Significativa, v: 31, n. 3, p. 198-202. 2009.

GUIMARÃES, C. C. Experimentação no ensino de Química: caminhos e descaminhos rumo à aprendizagem significativa. Química Nova na Escola, v. 31, n.3, ago. 2009.

HERRERO, J. F. A.; BAUTISTA, C. V. Utilización de La contextualización mediante el uso de demostraciones experimentales para mejor ar la percepción y la actitudhacia La Quimica de los futuros maestros. Enseñanza de las Ciencias, v.37. n. 3. p. 73-88, 2019.

HODSON, D.Hacia um enfoque más crítico Del trabajo de laboratório.Enseñanza de las Ciencias, Barcelona, v.12, n. 13, p.299-33. 1994.

JIMÉNEZ-ALEIXANDRE, M. P. A argumentação sobre questões sócio-científicas: processos de construção e justificação do conhecimento na aula. Educação em Revista, n. 43, p.13-33. Jun. 2006.

KELLY, G. Inquiry, activity and epistemic practice. IN: Inquiry Conference on Developing a Consensus Research Agenda, 16-18 de fev. de 2005, New Brunswick, New Jersey, EUA. 
KUHN, T. S. A estrutura das Revoluções científicas. São Paulo: Perspectiva, 1998.

LORENCINI JR, A. O Professor e as perguntas na construção do discurso reflexivo em sala de aula. Dissertação de doutorado. Faculdade de Educação da USP, 2000.

LOURENÇO FILHO, M. B. Introdução ao Estudo da Escola Nova: bases sistemas e diretrizes da pedagogia contemporânea. 13. ed. São Paulo: Melhoramentos, 1978.

LÜDCKE, M.; ANDRÉ, M. Pesquisa em Educação: Abordagens qualitativas. São Paulo: EPU, 1986.

MALDANER, O. A. A formação inicial e continuada de professores de Química: professores/pesquisadores. 4 ed. Ijuí: Editora Unijuí, 2013.

MALDANER, O. A.; ZANON, L. B.; AUTH, M. A. Situação de Estudo: uma organização do ensino que extrapola a formação disciplinar em Ciências. In: MORAES, ROQUE; MANCUSO, RONALDO. (Orgs.). In: Educação em Ciências: produção de currículos e formação de professores. Ijuí: Unijuí, 2004. p.43-64.

MARTINS, J. S. O trabalho com projetos de pesquisa. 6. ed. Campinas: Papirus,2009.

MATURANA, H.; VARELA, F. A árvore do conhecimento: as bases biológicas da compreensão humana. 2. ed. São Paulo: Palas Athena, 2005.

MAUÉS, E.; LIMA, M. E. C. Atividades Investigativas nas séries iniciais. Presença Pedagógica, v.12, n.72, nov./dez. 2006.

MEDEIROS, M. DE A.; LOBATO, A. C. Contextualizando a abordagem de radiações no ensino de química. Revista Ensaio. v.12, n.03, p.65-84, 2010.

MESSEDER NETO; PINHEIRO, B. C. S; ROQUE, N. F. Improvisações Teatrais no Ensino de Química: Interface entre Teatro e Ciência na Sala de Aula. Química nova na Escola, v. 35, n. 2, p. 100-106, mai. 2013.

MOLINA, J. A. L.; JAIME, J. M. L.; BERZOSA, I. S. Investigación Didáctica. La caracterización del ambiente de aprendizaje em um laboratório de química general mediante métodos de investigación social. Enseñanza de Las Ciencia. v.30. n. 1. p. 05-22, 2012.

MOLINA, M.; CASTRO, E.; MOLINA, J.; CASTRO, E. Uma cercamiento a La investigación de deseño a través de los experimentos de enseñanza. Enseñanza de las Ciencias, v. 29 n. 1. p. 75-88, 2011.

MONTEIRO, P.C. RODRIGUES, M.A., SANTIN FILHO, O. Experimentos com abordagem investigativa propostos por licenciandos em Química.IN: XI Encontro Nacional de Pesquisa em Educação em Ciências. Universidade Federal de Santa Catarina, Florianópolis, SC -julho de 2017. Anais[...] Florianópolis, 2017. Disponível em: < http://abrapecnet. org.br/enpec/xi-enpec/anais/resumos/R1530-1.pdf>. Acesso em 13 de março de 2021. 
MORAES, M. C. As novas tecnologias da Informação e a Capacitação de professores. Washington/DC, 1997.

MORAES, R. Cotidiano no Ensino de Química: superações necessárias. In: GALIAZZI, Maria do Carmo et al (Orgs.). Aprender em rede na educação em ciências. Ijuí: Unijuí. p.15-34, 2008;

MORAES, R. É Possível Ser Construtivista no Ensino de Ciências? In: MORAES, R. (org.). Construtivismo e ensino de Ciências. Porto Alegre: EDIPUCRS, p. 103-30, 2000.

MORAN, J. M. Mudando a educação com metodologias ativas. In: Convergências Midiáticas, Educação e Cidadania: aproximações jovens. Coleção Mídias Contemporâneas. 2015 Disponível em: http://www2.eca.usp.br/moran/wp-content/uploads/2013/12/ mudando moran.pdf. Acessado em 12 maio 2020.

MORAN, J. M. A educação que desejamos: novos desafios e como chegar lá. 5. ed. Campinas, SP: Papirus, 2011.

MORDEGLIA, C.; MENGASCINI, A. Caracterización de prácticas experimentales em la escuela a partir del discurso de docentes de primaria y secundaria. Enseñanza de las Ciencias, v. 32. n. 2. p. 71-89, 2014.

MOREIRA, M. A. A teoria da aprendizagem significativa e sua implementação em sala de aula. Brasília: Editora da UnB. 2006.

MOREIRA, M. A. Teorias de Aprendizagem. São Paulo. Editora Pedagógica e Universitária. 2011.

MORI, R. C.; CURVELO, A. A. S. A Experimentoteca do Centro de Divulgação Científica e Cultural (CDCC-USP) e o Ensino por Investigação: Compromissos Teóricos e Esforços Práticos. Revista Brasileira de Pesquisa em Educação em Ciências, v. 18. n. 3. p. 795$818,2018$.

MOURA, K. F. A.; DURÕES, J. A. S. Investigação no ensino médio: sistemas de hidroponia em horta escolar para discussão de conceitos químicos. Experiências em Ensino de Ciências, v.14. n. 2. p. 582-592, 2019.

NOVAK, J. D. Teoría y Práctica de La educación. Madrid, Alianza Editorial.1988.

NÓVOA, A. Formação de professores e profissão docente. In A. Nóvoa (Ed) Os professorese a sua formação ( $3^{\circ}$ ed.) Lisboa. Dom Quixote, 15-33. 1997.

OLIVEIRA, J. R. S. Contribuições e abordagens das atividades experimentais no ensino de ciências: reunindo elementos para a prática docente.Acta Scientiae, v.12, n.1, jan./ 
jun. 2010. Disponível em :http://w3.ufsm.br/laequi/wpcontent/uploads/2015/03/contribui $\% \mathrm{C} 3 \% \mathrm{~A} 7 \% \mathrm{C} 3 \% \mathrm{~B} 5$ es-e-abordagens-de-atividadesexperimentais.pdf. Acessado em 12 maio2020.

PEREZ, B. C.; ALEIXANDRE, M. P. J. Desafíos planteados por las atividades abiertas de indagación em el laboratório: articulación de conocimientos teóricos y prácticos em lasprácticascientíficas. Ensenãnza de las Ciencias., v. 33. n. 01. p. 63-84. 2015.

PERSICH, G. D. O. Projeto Investigativo Interdisciplinar Conexão Delta e as Potencialidades do Ensino por Investigação no Ensino Médio. Dissertação Pós- graduação em Educação em Ciências: Química da Vida e Saúde da Universidade Federal de Santa Maria. Santa Maria-RS 2017. Disponível em: https://repositorio.ufsm.br/bitstream/handle/1/13709/DIS_PPGEC 2017_PERSICH_GRACIELI.pdf? sequence=1\&isAllowed=y. Acessado em 14 maio 2020.

PINOTT, R. Educação ambiental para o século XXI: no Brasil e no mundo. São Paulo: Blucher, 2010.

POSTIGO, D. F., GRECA, I. M. Uso de la metodología de la indagación para la enseñanza de nociones sobre fuerza sen primer ciclo de la escuela primaria.Ensenãnza de las Ciências. V. 26, n.Extra, p. 265-273, 2014.

POZO, J. I.; CRESPO, M. Á. G. A aprendizagem e o ensino de ciências: do conhecimento cotidiano ao conhecimento científico. 5. ed. Artmed: Porto Alegre, 2009.

QUEIROZ, S. L.; ALMEIDA, M. J. P. M. Do fazer ao compreender ciências: reflexões sobre o aprendizado de alunos de iniciação científica em química. 2004. Disponível em:

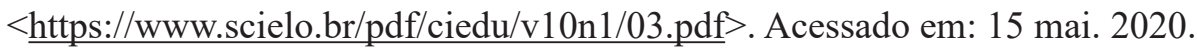

RIAL, M. A. L.; LIRES, M. M. A.; CORREA, A. A.; RODRIGUEZ, U. P. Aprender a interpretar La acidificación oceânica com recursos on-line y experimentación contextualizada. Enseñanza de Las Ciencia, v. 37. n. 2. p. 189-209, 2019.

RODRIGUEZ, L. G.; PÉREZ, B. C. Aprendizage de lãs reaciones químicas a través de atividades de indagación em el laboratório sobre cuestiones de la vida cotidiana. Enseñanza de las Ciencias, v.34. n.3. p. 143-160. 2016.

SANTOS, L. P. A relação da Geografia e o conhecimento cotidiano vivido no Lugar. Geografia Ensino \& Pesquisa, v. 16, n. 3, p. 107-122, set./dez. 2012.

SASSERON, L. H.; MACHADO, V. F. Alfabetização científica na prática: inovando a forma de ensinar física. São Paulo: Livraria da Física, 2017. 
SCHNETZLER, R. P. Pesquisa em Ensino de Química no Brasil: Conquistas e Perspectivas. Química Nova, 25 (Suplemento 1), p. 14-24. 2002.

SENRA, C. P.; BRAGA, M. Pensando a natureza da ciência a partir de atividades experimentais investigativas numa escola de formação profissional. Caderno Brasileiro de Ensino de Física, v.31. n. 1. p. 7-29. 2014.

SILVA, A. DA C. T. Estratégias Enunciativas em Salas de Aulas de Química: Contrastando professores de estilos diferentes. 353f. Tese (doutorado em Educação) Faculdade de Educação - UFMG, Minas Gerais, 2008.

SILVA, G. M. Metodologia de ensino de disciplinas da área de ciências da natureza, matemática e suas tecnologias do ensino médio: física, química e biologia. Teia do Saber - USP. São José do Rio Preto, 2005.

SILVA, R. M. G. Y SCHNETZLER, R. P. Constituição de professores universitários de disciplinas sobre o ensino de Química. Química Nova, 28(6), p. 1123-1133, 2005.

SILVA, R. T., et al. Contextualização e experimentação: uma análise dos artigos publicados na seção "Experimentação no Ensino de Química" da Revista Química Nova na Escola 2000-2008. Ensaio: Pesq. Educ. Ciências. v. 11, n. 2, p. 1-22, 2009.

SOLBES, J.; MONTSERRAT, R.; FURIÓ, C. El desinterés del alumna do hacia el aprendizaje de la ciencia: implicaciones em su enseñanza. Didáctica de las Ciencias experimentales y sociales. n.21, p. 91-117, 2007.

SUART, R. C. A experimentação no ensino de Química: conhecimentos e caminhos. In: SANTANA, E.; SILVA, E. (Org.). Tópicos em Ensino de Química. São Carlos: Pedro \& João Editores, 2014. p. 63-88.

SUART, R. C. Habilidades cognitivas manifestadas por alunos do ensino médio de química em atividades experimentais investigativas. 2008. 218f. Dissertação (Mestrado em Ensino de Ciências) - Universidade de São Paulo, São Paulo, 2008.

TOLEDO, E. J. L.; FERREIRA, L. H. A atividade investigativa na elaboração e análise de experimentos didáticos. Revista Brasileira de Ensino de Ciência e Tecnologia, v.9. n. 2. p. 108-130. 2016.

SUART, R. C.; MARCONDES, M. E. R. A manifestação de habilidades cognitivas em atividades experimentais investigativas no ensino médio de química. Ciência \& Cognição. v. 14, p. 50-74, 2009.

TORRES, T.; DUQUE, J.; ISHIWA, K.; SÁNCHEZ, G.; SOLAZ-PORTOLÉS, J. J.; SANJOSÉ, V. Preguntas de losestudiantes de educación secundaria ante dispositivos experimentales. Enseñanza de Las Ciencia, v. 30. n.1. p. 49-60, 2012. 
VARELA, L. K. DE S. L.; SOUZA, L. G. S. O uso da cozinha como laboratório alternativo para o ensino de química. In: Congresso Nacional de Educação, 5., 2018, Fortaleza. Anais[...] Fortaleza: Conedu, 2018. v. 1, p. 1 - 4.

ZABALA. A. A prática educativa: como ensinar. Trad. Ernani F. da Rosa - Porto Alegre: ArtMed, 1998.

\section{DADOS DAS AUTORAS}

\section{Ana Flávia Correa leão}

Mestranda da Universidade Federal do Pampa (UNIPAMPA), Caçapava do Sul/RS-Brasil. leaoanaflavia5@gmail.com

\section{Mara Euisângela Jappe GoI}

Doutora em Educação pela Universidade Federal do Rio Grande do Sul (UFRGS). Docente da Universidade Federal do Pampa (UNIPAMPA), Caçapava do Sul/RS-Brasil. maragoi28@gmail.com

Submetido em: 05-06-2020

Aceito em: 31-03-2021 